\title{
Anthropometric and lifestyle factors associated with white-coat, masked and sustained hypertension in a Chinese population
}

\author{
Gu-Liang Wang ${ }^{a}$, Yan Li ${ }^{a}$, Jan A. Staessen ${ }^{b}$, Lu Lü and Ji-Guang Wang ${ }^{a}$
}

Objective We investigated to what extent anthropometric and lifestyle factors contributed to the classification of Chinese individuals into groups with white-coat, masked and sustained hypertension (HT).

\begin{abstract}
Methods We measured the office and ambulatory blood pressure (BP) in 694 Chinese enrolled in the JingNing population study (45.7\% men; mean age, 48.4 years). In multivariate-adjusted analyses, we determined the correlates of both types of BP and the factors contributing to white-coat HT (conventional and daytime BP $\geq 140 / 90$ and $<135 / 85 \mathrm{mmHg}$, respectively), masked $\mathrm{HT}(<140 / 90$ and $\geq 135 / 85 \mathrm{mmHg}$ ) and sustained HT ( $\geq 140 / 90$ and $\geq 135 / 85 \mathrm{mmHg})$, relative to normotension $(<140 / 90$ and $<135 / 85 \mathrm{mmHg}$ ).
\end{abstract}

Results In continuous analyses, the conventional and daytime BPs were positively associated with age, body mass index and urinary sodium, and inversely with urinary potassium. The prevalence of white-coat, masked and sustained HT was $7.8,10.8$, and $35.0 \%$, respectively. In line with the continuous analyses, the risk of sustained hypertension increased with age [odds ratio (OR), 2.11 per 10 years], body mass index (OR, $\left.1.27 \mathrm{per} 1 \mathrm{~kg} / \mathrm{m}^{2}\right)$ and urinary sodium (OR, 1.18 per $50 \mathrm{mmol} /$ day), but was inversely associated with urinary potassium (OR, 0.34 per

\section{Introduction}

Current guidelines define normotension and sustained hypertension as a consistently normal or consistently elevated blood pressure on conventional and ambulatory measurement, respectively [1]. White-coat hypertension is a raised office blood pressure in the presence of a normal daytime blood pressure, whereas masked hypertension is an elevated daytime blood pressure with normal office blood pressure [1]. Follow-up studies of populations [2,3] and patient cohorts [4,5] demonstrated a gradual increase in cardiovascular risk from normotension over white-coat hypertension and masked hypertension to sustained hypertension.

The prevalence of white-coat hypertension and masked hypertension was 17.6 and $8.5 \%$ in a European population [6]; it was 12.8 and $16.6 \%$ in a Japanese population [7]. In the International Database on Ambulatory Blood Pressure Monitoring [8], the probability of white-coat hypertension increased with age and female sex, whereas at that time (1991-1993) masked hypertension had
$25 \mathrm{mmol} /$ day). Furthermore, the risk of white-coat and masked HT increased with age (OR, 1.79 and 1.40, respectively) and body mass index (OR, 1.14 and 1.12). Women were less likely to have masked hypertension than men (OR, 0.39).

Conclusions Sex, age, body mass index, and urinary sodium and potassium excretion contribute to the risk of white-coat, masked and sustained HT in Chinese. J Hypertens 25:2398-2405 (C) 2007 Wolters Kluwer Health | Lippincott Williams \& Wilkins.

Journal of Hypertension 2007, 25:2398-2405

Keywords: ambulatory blood pressure monitoring, masked hypertension, sustained hypertension, white-coat hypertension

${ }^{a}$ Centre for Epidemiological Studies and Clinical Trials, Ruijin Hospital, Shanghai Jiaotong University Medical School, China and ${ }^{b}$ Studies Coordinating Centre, Division of Hypertension and Cardiovascular Rehabilitation, Department of Cardiovascular Diseases, University of Leuven, Belgium

Correspondence to Ji-Guang Wang MD, PhD, Shanghai Institute of Hypertension, Ruijin 2nd Road 197, Shanghai 200025, China Tel: +86 2164370045 ext. 610911; fax: +86 2164662193 ; e-mail: jiguangwang@netscape.net

Received 8 January 2007 Revised 5 July 2007 Accepted 11 July 2007

not yet been defined as a separate clinical entity. To our knowledge, only two Chinese population studies $[9,10]$ included both conventional and ambulatory blood pressure measurements, but did not address the prevalence and determinants of white-coat and masked hypertension. In view of the prognostic significance of these conditions [2-5], we analysed the current database of the JingNing population survey [9] to investigate the prevalence and determinants of white-coat, masked and sustained hypertension. We also analysed the anthropometric and lifestyle determinants of conventional and ambulatory blood pressure in an attempt to understand what drives the cross-classification into white-coat, masked and sustained hypertension.

\section{Methods}

Study population

Within the framework of our ongoing Chinese study on genes in hypertension [11], from 2003 to 2005, we recruited participants from 14 villages in the JingNing County, a rural area approximately $500 \mathrm{~km}$ south of 
Shanghai. The Ethics Committee of Ruijin Hospital and Shanghai Jiaotong University Medical School approved the study. We invited all villagers with a minimum age of 12 years to take part. Of 2059 eligible subjects, 1490 gave informed written consent. The participation rate was therefore $72.4 \%$.

At the time of writing this report, 733 participants had their ambulatory blood pressure measured. Compared with subjects who were scheduled to undergo ambulatory blood pressure monitoring at a later stage, the current participants included more women (54.3 versus $48.0 \%$, $P=0.02)$. They were also older ( 48.1 versus 41.5 years, $P<0.0001)$ and included a higher proportion of hypertensive patients $(42.3$ versus $15.7 \%, P<0.0001)$.

Of 733 participants with ambulatory blood pressure recordings, we excluded 39 subjects from analysis, because their age was less than 18 years $(n=8)$, or their ambulatory recordings had a duration of less than $20 \mathrm{~h}$ $(n=1)$, or included fewer than 10 daytime $(n=2)$ or 5 night-time $(n=14)$ readings, or because the subjects lacked measurements of important covariates $(n=14)$. Thus, the number of participants included in the present analysis totalled 694.

\section{Ambulatory blood pressure monitoring}

In keeping with the methods used in other population studies [12], we programmed validated [13] SpaceLabs 90207 monitors (SpaceLabs Inc., Redmond, Washington, USA) to obtain oscillometric blood pressure readings at 20-min intervals from 0800 until $2200 \mathrm{~h}$ and every $45 \mathrm{~min}$ from 2200 to $0800 \mathrm{~h}$. Each month, we checked the calibration of these devices against a mercury column. If the ambulatory recordings were longer than a full day, we only analysed the first $24 \mathrm{~h}$.

Using short, fixed, clock-time intervals [14], we defined daytime and night-time as the intervals ranging from 0800 to $1800 \mathrm{~h}$ and from 2200 to $0400 \mathrm{~h}$, respectively [9]. We demonstrated previously that in our Chinese rural population, the blood pressure levels during daytime and night-time defined in this way were, on average, within less than $0.5 \mathrm{mmHg}$ of the awake and asleep blood pressures [9]. Intra-individual means of the ambulatory blood pressures were weighted by the time interval between successive readings [15].

In line with current guidelines for the diagnosis of hypertension [1], we defined conventional hypertension as a blood pressure level equal to or exceeding $140 \mathrm{mmHg}$ systolic or $90 \mathrm{mmHg}$ diastolic. The corresponding thresholds for daytime ambulatory hypertension were $135 \mathrm{mmHg}$ systolic and $85 \mathrm{mmHg}$ diastolic. Normotension and sustained hypertension were a consistently normal or a consistently elevated blood pressure on conventional and ambulatory measurement. White-coat hypertension was a raised conventional blood pressure in the presence of a normal daytime blood pressure [1]. Masked hypertension was an elevated daytime ambulatory blood pressure with normal conventional blood pressure [1]. If on conventional or ambulatory measurement, systolic and diastolic blood pressures belonged to different categories, we used the higher category to classify the subject. Patients on antihypertensive drug treatment $(n=96)$ were included in the group with sustained hypertension.

\section{Conventional blood pressure measurement}

At a local examination centre in each village, one physician (G.L.W.) measured each participant's blood pressure according to the 2003 European guidelines [1]. After the subjects had rested for at least $5 \mathrm{~min}$ in the sitting position, he measured systolic and phase $\mathrm{V}$ diastolic blood pressure to the nearest $2 \mathrm{mmHg}$ by auscultation of the Korotkoff sounds, using a standard mercury sphygmomanometer. We averaged five consecutive blood pressure readings in each participant for analysis.

\section{Other measurements}

We administered a standardized questionnaire to collect information on each participant's smoking habits, alcohol intake, physical activity and use of medications. Using published tables [16], we computed the energy spent in physical activity from each subject's body weight, the time devoted to work and sports, and the type of physical activity. Body mass index was weight in kilograms divided by height in metres squared. Within 2-3 days of the visit at the examination centre, the participants collected a 24-h urine sample in a wide-neck plastic container for the measurement of sodium, potassium and creatinine.

\section{Statistical analysis}

For database management and statistical analyses, we used SAS software, version 9.1 (SAS Institute Inc., Cary, North Carolina, USA). We reported the central tendency and spread of non-normally distributed data as the median and the 5th to 95th percentile interval. We normalized the distribution of energy expenditure in physical activity by a logarithmic transformation. We compared means and proportions by a large sample z-test and Fisher's exact test, respectively. We performed multivariate-adjusted comparisons between groups, using a generalized linear model providing $P$ values for overall and pairwise differences.

We searched for significant determinants of the conventional and the daytime ambulatory blood pressures, using stepwise linear regression with the $P$ value for independent variables to enter and stay in the model set at 0.10 . We considered as possible covariates sex, age, body mass index, current smoking and drinking, the energy 
expenditure in physical activity, and the urinary sodium and potassium excretion. We performed multivariate analysis of variance to compare the parameters of the regression equations with the conventional and daytime ambulatory blood pressures as dependent variables.

Finally, while considering the same covariates as in multiple linear regression, we ran a stepwise logistic regression procedure with the normotensive participants as the reference group to identify the factors determining the classification of subjects into those with white-coat, masked and sustained hypertension. As in the linear regression analysis, we set the $P$ value for variables to enter and stay in the model at 0.10 .

\section{Results}

\section{Characteristics of the participants}

The 694 participants included 317 men (45.7\%) and 297 patients with hypertension on conventional blood pressure measurement (42.8\%), of whom 96 (32.3\%) were taking antihypertensive drugs. Age ranged from 18 to 86 years. The 24-h and night-time systolic and diastolic blood pressures were similar in men and women $(0.13<P<0.36)$. In the whole study population, mean $( \pm \mathrm{SD})$ systolic and diastolic levels were $122.9 \pm$ $17.1 \mathrm{mmHg}$ and $78.3 \pm 10.8 \mathrm{mmHg}$ for the 24-h blood pressure and $113.8 \pm 19.0 \mathrm{mmHg}$ and $71.2 \pm 12.0 \mathrm{mmHg}$ for the night-time blood pressure. Table 1 lists the other blood pressure measurements, anthropometric characteristics, and the urinary excretion of sodium and potassium for men and women, separately. Of the 7020 conventional systolic and diastolic blood pressure readings obtained by the single observer, $22.4 \%$ ended in $0,20.3 \%$ in $2,18.3 \%$ in $4,20.3 \%$ in 6 , and $18.6 \%$ in 8 , demonstrating a lack of terminal-digit preference.

Compared to women, men more frequently reported smoking $(0$ versus $65.0 \% ; P<0.001)$ and alcohol intake

Table 1 Characteristics of the study population

\begin{tabular}{lccc}
\hline & $\begin{array}{c}\text { Men } \\
(n=317)\end{array}$ & $\begin{array}{c}\text { Women } \\
(n=377)\end{array}$ & $P$ \\
\hline Demographic characteristics & & & \\
Age (years) & $50.0 \pm 15.5$ & $47.2 \pm 14.4$ & 0.01 \\
Body height (cm) & $161.1 \pm 6.2$ & $151.5 \pm 5.8$ & $<0.001$ \\
Body weight (kg) & $57.6 \pm 9.2$ & $52.4 \pm 8.4$ & $<0.001$ \\
Body mass index (kg/m $\left.{ }^{2}\right)$ & $22.1 \pm 3.0$ & $22.8 \pm 3.0$ & 0.006 \\
Office measurements & & & \\
Systolic blood pressure (mmHg) & $134.6 \pm 25.2$ & $136.2 \pm 28.0$ & 0.44 \\
Diastolic blood pressure (mmHg) & $79.8 \pm 13.2$ & $80.1 \pm 14.5$ & 0.75 \\
Pulse rate (beats/min) & $68.7 \pm 10.4$ & $71.3 \pm 9.7$ & $<0.001$ \\
Daytime ambulatory measurements & & & \\
Systolic blood pressure (mmHg) & $129.5 \pm 15.5$ & $126.9 \pm 18.5$ & 0.04 \\
Diastolic blood pressure (mmHg) & $83.3 \pm 9.9$ & $82.0 \pm 11.7$ & 0.11 \\
Pulse rate (beats/min) & $79.1 \pm 12.1$ & $80.1 \pm 9.6$ & 0.22 \\
24-Hour urinary measurements & & & \\
Volume (I) & $1.25 \pm 0.54$ & $1.12 \pm 0.44$ & $<0.001$ \\
Sodium (mmol/day) & $164.4 \pm 81.4$ & $168.0 \pm 72.8$ & 0.54 \\
Potassium (mmol/day) & $25.4 \pm 10.3$ & $25.0 \pm 10.3$ & 0.63 \\
Creatinine (mmol/day) & $9.07 \pm 3.21$ & $6.76 \pm 2.13$ & $<0.001$ \\
\hline & & & \\
\hline
\end{tabular}

Values are mean $\pm S D$.
(36.9 versus $75.4 \% ; P<0.001)$. In smokers, median tobacco use was 20 cigarettes per day (5th-95th percentile interval, 4-40). In drinkers, median alcohol consumption was $20 \mathrm{~g} /$ day (5th-95th percentile interval, 4-140). Energy expenditure in physical activity was similar $(P=0.08)$ in men (geometric mean, $2904 \mathrm{kcal} /$ day; 5 th-95th percentile interval, $677-5932 \mathrm{kcal} /$ day) and women (2643 kcal/day; $977-5342 \mathrm{kcal} /$ day).

\section{Characteristics of participants by subtype of ambulatory hypertension}

Of the 694 participants, 322 (46.4\%) were normotensive. The prevalence of white-coat, masked and sustained hypertension was 54 (7.8\%), $75(10.8 \%)$ and $243(35.0 \%)$, respectively. Figure 1 shows the diurnal blood pressure profile for the four blood pressure categories.

Compared to the normotensive group (Table 2), patients with white-coat, masked or sustained hypertension were older, and those with sustained hypertension also had higher body mass index. Patients with sustained hypertension had a lower energy expenditure in physical activity than the normotensive group. Women were under-represented among patients with masked hypertension. Potassium excretion was lower in patients with white-coat or sustained hypertension (Table 2).

\section{Determinants of the conventional and daytime ambulatory blood pressures}

In the further analyses in which blood pressure was used as a continuous variable, we excluded the 96 patients who were on antihypertensive treatment. In men and women alike, systolic blood pressure on conventional and daytime ambulatory measurement increased with age and body mass index (Table 3). The slope of the association of systolic blood pressure with age (Fig. 2) was significantly steeper for the conventional than the daytime ambulatory blood pressure. Systolic blood pressure in men also increased with higher urinary sodium excretion and lower urinary potassium output (Table 3).

In men as well as women, diastolic blood pressures on conventional and daytime ambulatory measurement were curvilinearly related to age and increased with body mass index (Table 3). In women, there was a significant difference in the curvilinear association of diastolic blood pressure with age between the conventional and daytime blood pressures. Below age 35 , the slope with age was steeper for the conventionally measured diastolic blood pressure (Fig. 2). In men, the slope of diastolic blood pressure on body mass index was steeper for the office measurements, and both conventional and daytime diastolic blood pressure were higher in subjects drinking alcohol (Table 3). In women, the conventional diastolic blood pressure was also inversely associated with urinary potassium excretion. 

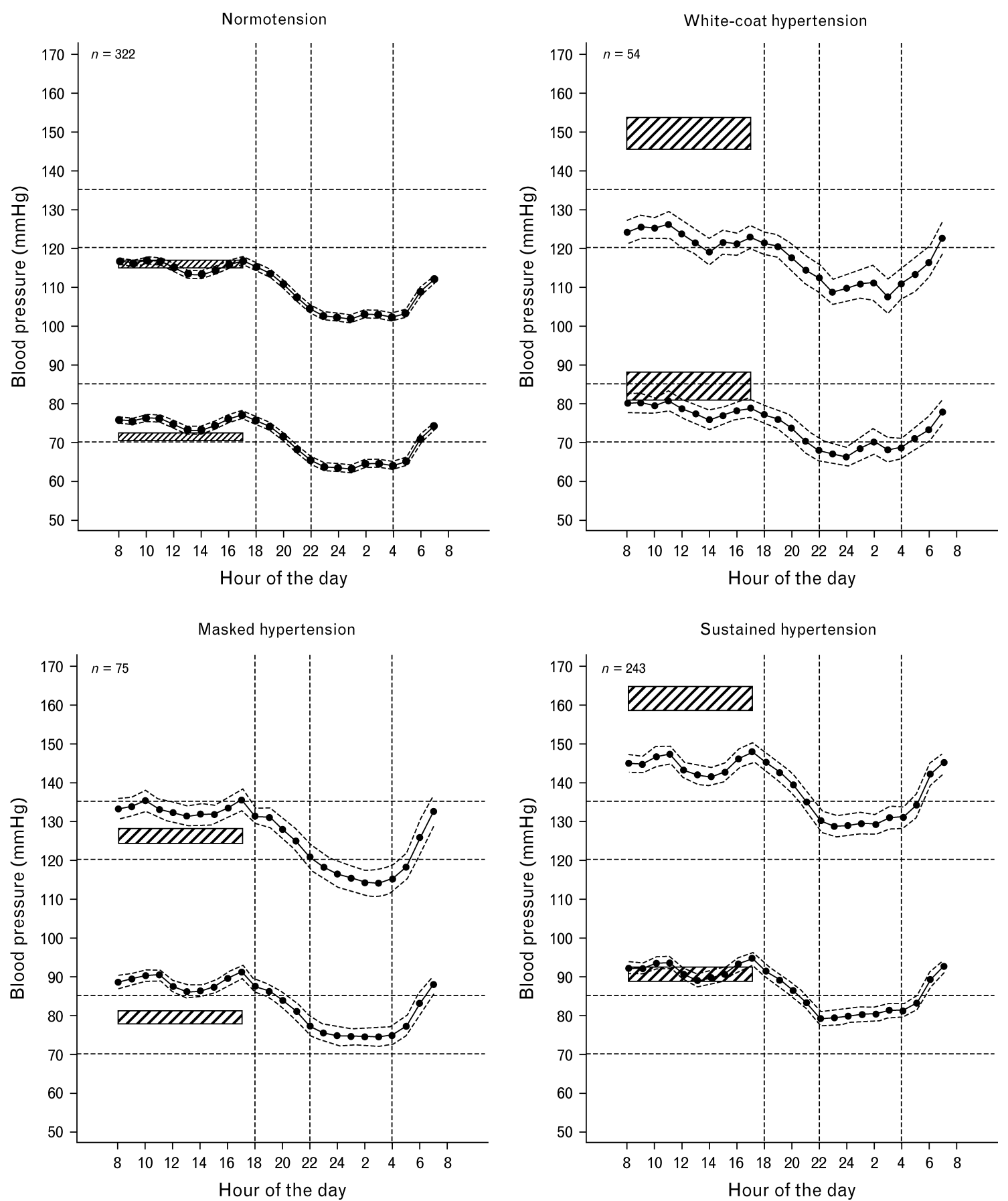

Twenty-four-hour blood pressure profiles by blood pressure category. Values are expressed as hourly means with $95 \%$ confidence interval. In each graph, upper values are systolic blood pressure and lower values, diastolic blood pressure. Daytime and night-time ranged from 0800 to $1800 \mathrm{~h}$ and from 2200 to $0400 \mathrm{~h}$, respectively, as indicated by the vertical dotted lines; $n$ indicates the number of subjects within each category. The shaded bands indicate the $95 \%$ confidence interval of the conventionally measured blood pressure.

\section{Factors driving the classification into blood pressure groups}

Next, with normotensive subjects as the reference group, we searched for the factors contributing to the classification of patients into those with white-coat, masked and sustained hypertension (Table 4). In line with the continuous analyses presented in Table 3 , in men and women combined, the risk of sustained hypertension increased with age, body-mass index and urinary sodium excretion, but it was inversely associated with urinary 
Table 2 Characteristics of participants by blood pressure category

\begin{tabular}{|c|c|c|c|c|c|}
\hline & Normotension $(n=322)$ & White-coat HT $(n=54)$ & Masked HT $(n=75)$ & Sustained HT $(n=243)$ & $P$ \\
\hline Women $(n, \%)$ & $182(56.5)$ & $29(53.7)$ & $25(33.3)^{\dagger}$ & $141(58.0)$ & 0.002 \\
\hline Age (years) & $42.2 \pm 13.2$ & $53.0 \pm 15.0^{\dagger}$ & $48.9 \pm 14.0^{\dagger}$ & $55.5 \pm 13.9^{\dagger}$ & $<0.0001$ \\
\hline Body mass index $\left(\mathrm{kg} / \mathrm{m}^{2}\right)$ & $21.9 \pm 2.6$ & $22.5 \pm 2.7$ & $22.3 \pm 2.8$ & $23.3 \pm 3.4^{\dagger}$ & $<0.0001$ \\
\hline Daytime pulse rate (beats/min) & $79.9 \pm 10.4$ & $77.8 \pm 11.4$ & $83.0 \pm 11.0^{*}$ & $78.7 \pm 11.0$ & 0.01 \\
\hline Sodium excretion (mmol/day) & $169.3 \pm 77.4$ & $170.3 \pm 81.2$ & $177.0 \pm 81.8$ & $158.3 \pm 73.0$ & 0.19 \\
\hline Potassium excretion (mmol/day) & $26.8 \pm 11.0$ & $23.8 \pm 8.7^{*}$ & $26.6 \pm 10.5$ & $22.9 \pm 9.1^{\dagger}$ & $<0.0001$ \\
\hline Energy spent in physical activity (kcal/day) & $2859(1236-5534)$ & $3467(1737-6025)$ & $3090(977-6165)$ & $2398(138-5623)^{*}$ & 0.0007 \\
\hline Current smokers $(n, \%)$ & $97(30.1)$ & $13(24.1)$ & 28 (37.3) & $68(28.0)$ & 0.36 \\
\hline Current drinking $(n, \%)$ & $173(53.7)$ & $33(61.1)$ & $49(65.3)$ & $123(50.6)$ & 0.11 \\
\hline
\end{tabular}

$\mathrm{HT}$ indicates hypertension. Values are arithmetic mean $\pm \mathrm{SD}$, geometric mean (5th-95th percentile interval), or number of subjects (\%). $P$ values are for the overall differences between the four groups. Significance of the difference with the normotensive reference group: ${ }^{*} P<0.05 ;{ }^{\dagger} P<0.001$.

potassium output. Furthermore, in men and women combined, the risk of white-coat and masked hypertension increased with age and body mass index. Women were less likely to have masked hypertension than men.

Table 4 also lists the determinants of white-coat, masked and sustained hypertension for men and women, separately. The energy spent in physical activity was not a risk factor for masked hypertension in men $(P=0.37)$, women $(P=0.91)$, or in both sexes combined $(P=0.32)$.

\section{Sensitivity analysis}

After exclusion of 96 patients on antihypertensive drug treatment, the determinants of white-coat, masked and sustained hypertension reported in Table 4 remained unaltered. Furthermore, we also replicated the results shown in Table 4 when we defined the daytime ambulatory hypertension as a daytime blood pressure level of at least $130 \mathrm{mmHg}$ systolic or $80 \mathrm{mmHg}$ diastolic.

\section{Discussion}

The key finding of our current study is that blood pressure both on conventional and on ambulatory measurement is continuously distributed in the popu- lation at large. The determinants of blood pressure analysed as a continuous variable therefore also have an impact on the cross-classification of subjects according to the arbitrary thresholds for conventional and daytime ambulatory blood pressure as proposed in current hypertension guidelines. In our continuous analyses, the conventional and daytime blood pressures were positively associated with age, body mass index and urinary sodium excretion, and inversely correlated with urinary potassium. In line with these findings, the risk of sustained hypertension increased with age, body mass index and higher sodium excretion, and decreased proportionally to urinary potassium output.

Our current findings are in agreement with analyses of a Flemish population sample and Irish bank employees, published in 1992 [17]. In these cohorts, age ranged from 17 to 81 years, and body mass index from 16.6 to $40.2 \mathrm{~kg} / \mathrm{m}^{2}$. The $24-\mathrm{h}$ ambulatory blood pressure was significantly lower than the blood pressure measured by nurses in both the Belgian and Irish subjects. When blood pressure was measured by an observer, the wellestablished relations between systolic and diastolic blood pressure and both age and body mass index were evident.

Table 3 Determinants of conventional and daytime blood pressure in subjects without antihypertensive medication

\begin{tabular}{|c|c|c|c|c|c|c|}
\hline & \multicolumn{3}{|c|}{ Men $(n=281)$} & \multicolumn{3}{|c|}{ Women $(n=317)$} \\
\hline & Conventional & Daytime & $P$ & Conventional & Daytime & $P$ \\
\hline \multicolumn{7}{|l|}{ Systolic blood pressure } \\
\hline$R^{2}$ & 0.23 & 0.15 & & 0.28 & 0.16 & \\
\hline Intercept & 76.7 & 90.7 & & 72.3 & 83.4 & \\
\hline Age (years) & $0.647 \pm 0.084^{\S}$ & $0.338 \pm 0.053^{\S}$ & $<0.0001$ & $0.860 \pm 0.085^{\S}$ & $0.474 \pm 0.062^{\S}$ & $<0.0001$ \\
\hline Body mass index $\left(\mathrm{kg} / \mathrm{m}^{2}\right)$ & $1.112 \pm 0.436^{*}$ & $0.783 \pm 0.282^{\dagger}$ & 0.38 & $1.027 \pm 0.402^{*}$ & $0.821 \pm 0.295^{\dagger}$ & 0.62 \\
\hline Sodium excretion (mmol/day) & $0.052 \pm 0.020^{\dagger}$ & NS & NA & NS & NS & NA \\
\hline Potassium excretion ( $\mathrm{mmol} / \mathrm{day})$ & $-0.388 \pm 0.157^{*}$ & NS & NA & $-0.383 \pm 0.135^{\dagger}$ & NS & NA \\
\hline \multicolumn{7}{|l|}{ Diastolic blood pressure } \\
\hline$R^{2}$ & 0.14 & 0.10 & & 0.13 & 0.08 & \\
\hline Intercept & 28.0 & 47.5 & & 25.4 & 46.5 & \\
\hline Age (years) & $0.859 \pm 0.316^{\ddagger}$ & $0.804 \pm 0.250^{\dagger}$ & 0.68 & $1.775 \pm 0.316^{\S}$ & $0.877 \pm 0.263^{\ddagger}$ & 0.0001 \\
\hline $\mathrm{Age}^{2}\left(\right.$ years $\left.^{2}\right)$ & $-0.0084 \pm 0.0030^{\dagger}$ & $-0.0071 \pm 0.0024^{\dagger}$ & 0.38 & $-0.0174 \pm 0.0032^{\S}$ & $-0.0076 \pm 0.0027^{\dagger}$ & $<0.0001$ \\
\hline Body mass index $\left(\mathrm{kg} / \mathrm{m}^{2}\right)$ & $1.156 \pm 0.245^{\S}$ & $0.632 \pm 0.197^{\dagger}$ & 0.007 & $0.660 \pm 0.244^{\dagger}$ & $0.494 \pm 0.201^{*}$ & 0.66 \\
\hline Alcohol intake $(0,1)$ & $6.158 \pm 1.708^{\ddagger}$ & $3.125 \pm 1.353^{*}$ & 0.01 & NS & NS & NA \\
\hline Potassium excretion ( $\mathrm{mmol} / \mathrm{day})$ & NS & NS & NA & $-0.155 \pm 0.067^{*}$ & NS & NA \\
\hline
\end{tabular}

NS and NA indicate non-significant and not applicable, respectively. Values are partial regression coefficients ( \pm SE). $P$ values are for the comparison of the partial regression coefficients between the conventional and daytime blood pressure. The variables considered in the stepwise regression procedure were age, body mass index, the urinary sodium and potassium excretion, current smoking and drinking, and the energy expenditure in physical activity. Significance of the partial regression coefficients: ${ }^{*} P<0.05 ;{ }^{\dagger} P<0.01 ;{ }^{\ddagger} P<0.001 ;{ }^{\S} P<0.0001$. 

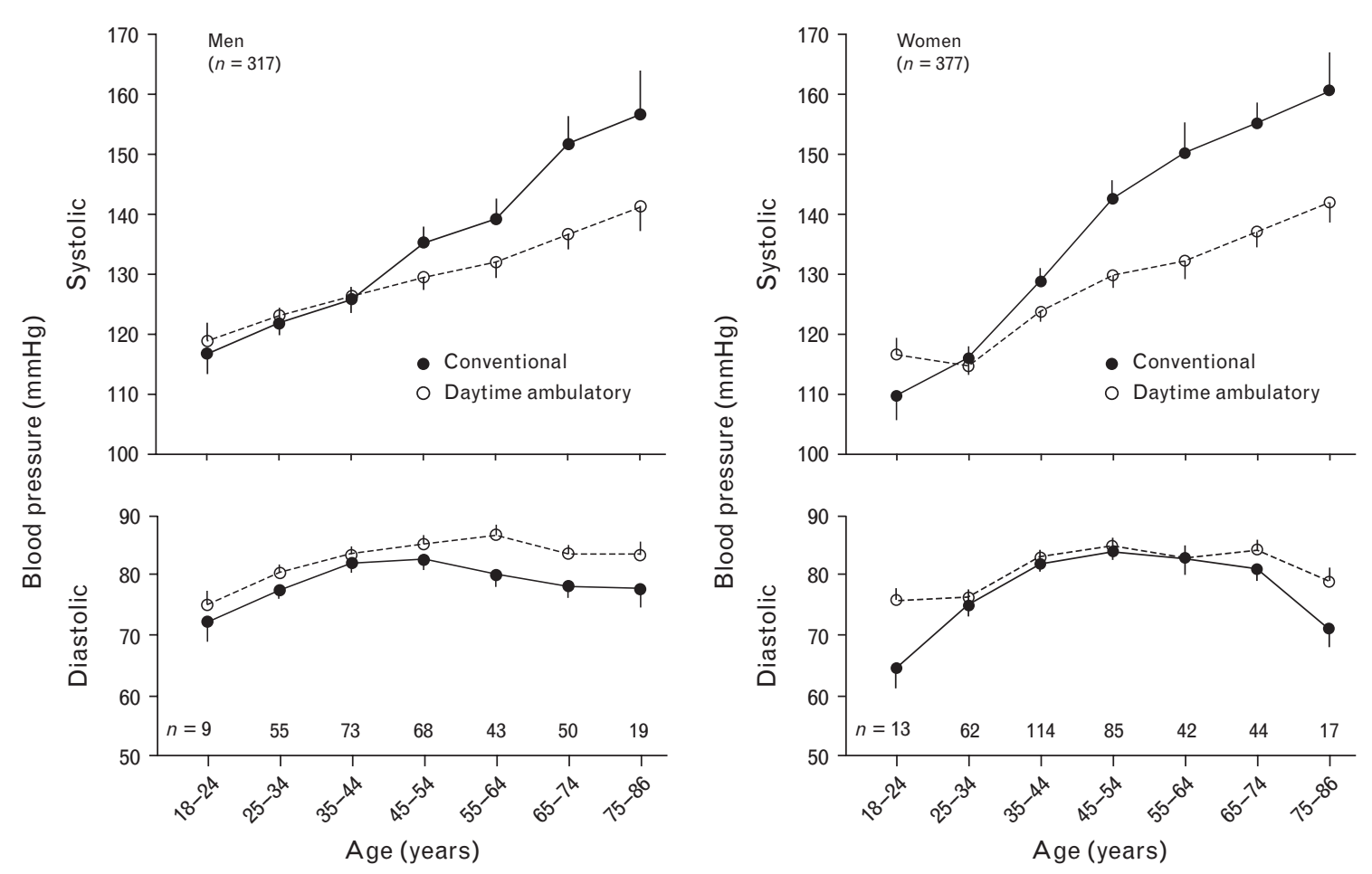

The conventional blood pressure (closed symbols) and the daytime ambulatory blood pressure (open symbols) by sex and age. Values are means \pm SE. Numbers indicate the subjects contributing to the means.

When these analyses were repeated using 24-h blood pressure recordings, the cross-sectionally assessed increment in blood pressure with age was weaker, especially in young and middle-aged subjects (20-60 years). The increase in the 24-h blood pressure with body mass index was also substantially reduced, compared to conventional blood pressure [17]. In our Chinese subjects, we also noticed a similar phenomenon, when using conventional blood pressure compared to daytime ambulatory blood pressure. This phenomenon is the opposite of regression dilution bias in prospective outcome studies, relating cardiovascular outcome to a single measurement of blood pressure as opposed to repeated measurement over time, which provide the so-called 'usual' blood pressure [18].

White-coat hypertension is a raised conventional blood pressure in the presence of a normal daytime ambulatory

Table 4 Determinants of white-coat, masked and sustained hypertension

\begin{tabular}{|c|c|c|c|c|c|c|}
\hline & \multicolumn{2}{|c|}{ White-coat hypertension } & \multicolumn{2}{|c|}{ Masked hypertension } & \multicolumn{2}{|c|}{ Sustained hypertension } \\
\hline & OR $(95 \% \mathrm{Cl})$ & $P$ & OR $(95 \% \mathrm{Cl})$ & $P$ & OR $(95 \% \mathrm{Cl})$ & $P$ \\
\hline \multicolumn{7}{|l|}{ Men } \\
\hline Age $(+10$ years $)$ & $1.61(1.18-2.20)$ & 0.003 & $1.26(1.00-1.59)$ & 0.046 & $1.99(1.61-2.47)$ & $<0.0001$ \\
\hline Body mass index $\left(\mathrm{kg} / \mathrm{m}^{2}\right)$ & $1.44(1.19-1.75)$ & 0.0002 & $1.19(1.04-1.37)$ & 0.01 & $1.31(1.17-1.46)$ & $<0.0001$ \\
\hline \multicolumn{7}{|l|}{ Women } \\
\hline Age $(+10$ years $)$ & $2.05(1.51-2.79)$ & $<0.0001$ & $1.70(1.24-2.33)$ & 0.0009 & $2.35(1.88-2.94)$ & $<0.0001$ \\
\hline Body mass index $\left(\mathrm{kg} / \mathrm{m}^{2}\right)$ & NS & & NS & & $1.22(1.12-1.35)$ & $<0.0001$ \\
\hline Urinary potassium excretion $(+25 \mathrm{mmol} /$ day $)$ & NS & & NS & & $0.40(0.20-0.81)$ & 0.01 \\
\hline \multicolumn{7}{|l|}{ Men and women } \\
\hline Female $(0,1)$ & NS & & $0.39(0.22-0.68)$ & 0.0008 & NS & \\
\hline Age $(+10$ years $)$ & $1.79(1.44-2.23)$ & $<0.0001$ & $1.40(1.16-1.69)$ & 0.0004 & $2.11(1.81-2.47)$ & $<0.0001$ \\
\hline Body mass index $\left(\mathrm{kg} / \mathrm{m}^{2}\right)$ & $1.14(1.02-1.28)$ & 0.02 & $1.12(1.01-1.23)$ & 0.03 & $1.27(1.18-1.37)$ & $<0.0001$ \\
\hline Urinary sodium excretion $(+50 \mathrm{mmol} /$ day $)$ & NS & & NS & & $1.18(1.00-1.39)$ & 0.049 \\
\hline Urinary potassium excretion $(+25 \mathrm{mmol} /$ day $)$ & NS & & NS & & $0.34(0.18-0.64)$ & 0.0009 \\
\hline
\end{tabular}

OR $(95 \% \mathrm{Cl})$ indicates the odds ratio with $95 \%$ confidence interval. Odds ratios were computed with normotensive subjects as the reference group and are mutually adjusted within blood pressure category. The variables considered in the stepwise regression procedure were sex (if applicable), age, body mass index, urinary sodium and potassium excretion, current smoking and drinking, and energy expenditure in physical activity. NS, non-significant. 
blood pressure [1]. Because the slope of daytime ambulatory blood pressure on age is weaker than for the conventional blood pressure, the prevalence of whitecoat hypertension must increase with older age. From a physiological point of view, the underlying mechanisms might be the decreasing efficacy of the baroreceptor reflex with age [19] and stiffer arteries with less elastic recoil to buffer the pressure wave during systole [20]. Similarly, because the slope of the daytime ambulatory blood pressure on body mass index is weaker than the corresponding slope of the conventional blood pressure, a higher body mass index also contributed to the likelihood of having white-coat hypertension. Increased sympathetic tone in obese people [21] might account for a more brisk arousal vis-à-vis the observer measuring the conventional blood pressure.

Masked hypertension is an elevated daytime ambulatory blood pressure in the presence of a normal clinic blood pressure [1]. We could not confirm our hypothesis that strenuous physical labour in a predominantly farming population increased the daytime ambulatory blood pressure and, in so doing, contributed to the $10.8 \%$ prevalence of masked hypertension. Indeed, we failed to demonstrate any significant association between the daytime ambulatory blood pressure and the energy spent in physical activity. The risk of masked hypertension was lower in women than men and, like that of white-coat hypertension, increased with age and body mass index. Across most epidemiological studies [22,23], age and body mass index are also major risk factors for progression from normotension to hypertension. In three studies, masked hypertension based on an awake or daytime blood pressure of at least $135 \mathrm{mmHg}$ systolic or $85 \mathrm{mmHg}$ diastolic conveyed a risk similar to that of sustained hypertension $[7,24,25]$. As recently demonstrated by Lurbe and colleagues in children and adolescents [26], masked hypertension is a precursor of sustained hypertension and left ventricular hypertrophy, and - pending evidence from randomized clinical trials - might become an indication for blood pressure-lowering drugs. In keeping with these prospective studies [24-26], our current findings suggest that masked hypertension is a true clinical entity related to the same risk factors as sustained hypertension and probably preceding the latter condition.

Several epidemiological surveys have noticed an independent and inverse relation between blood pressure and the urinary excretion of potassium [27,28], while the relation between blood pressure and sodium excretion in within-population studies has been reported to be positive, non-significant or even negative [27]. This was also the case when this relation between blood pressure and sodium excretion was studied within each of the 52 INTERSALT centres [29]. The inconsistency of the relation between blood pressure and sodium excretion in within-population studies might be ascribed to the presence or absence of other factors required for sodium to act as a pressor agent, such as for instance, the use of oral contraceptives [30]; to the large within-subject variability in diurnal sodium excretion [31]; or to confounding. In our Chinese population study, we consistently observed for conventional and daytime ambulatory blood pressure, as well as the risk of sustained hypertension, an inverse association with urinary potassium excretion. In addition, the risk of sustained hypertension was also associated with higher urinary sodium excretion. The high degree of standardization of our epidemiological methods, in particular the blood pressure measurements [9], and the low prevalence of other risk factors predisposing to hypertension, such as obesity and diabetes mellitus [9], might have facilitated the demonstration of associations between blood pressure and the urinary electrolytes.

The present study has to be interpreted within the context of its potential limitations. First, our cross-sectional study did not allow us to study the reproducibility of the classification according to office and daytime ambulatory blood pressure. In a 37-month follow-up study of 34 adolescents with masked hypertension [26], Lurbe and colleagues noticed that 18 became normotensive, whereas 13 had persistent masked hypertension and three progressed to sustained hypertension. Second, white-coat hypertension not only reflects the acute defence reaction and the white-coat phenomenon as originally described by Mancia and co-workers [32], but is also affected by other factors, such as measurement error and observer bias in the conventional blood pressure readings [33]. This explains why the white-coat effect is also quantitatively different from, and unrelated to, the actual rise in blood pressure, as directly recorded by beat-to-beat monitoring during a clinic visit [32]. However, in the present study, a single observer obtained all conventional blood pressure readings in a highly standardized fashion, as exemplified by the absence of terminal-digit preference. Third, the participants in the current study included $42.8 \%$ hypertensive patients. This proportion is larger than in the background population $(28.2 \%)$, and might therefore reflect some degree of selection; however, our findings remained consistent after we excluded patients on antihypertensive drug treatment.

In conclusion, the mechanisms driving the cross-classification of subjects according to the currently proposed arbitrary thresholds for office and daytime ambulatory blood pressure measurement can be understood by analysis of the factors that are related to these two types of blood pressure measurement in continuous analyses. Sex, age, body mass index, and urinary sodium and potassium excretion contribute to the risk of white-coat, masked and sustained hypertension in Chinese, and probably also in other populations. 


\section{Acknowledgements}

The JingNing study would not have been possible without the voluntary collaboration of the participants and the support of the local public health authorities.

The National Natural Science Foundation of China (grant 30571607), the Shanghai Commission of Science and Technology (grants 03JC14058 and 05ZR14100), the Shanghai 'Rising Star' (grant 06QA14043) and 'Dawn' projects, and the European Union (InGenious HyperCare, grant LSHM-CT-2006-037093) supported this research. J.A.S. is holder of the Pfizer Chair for Hypertension and Cardiovascular Research (http://www. kuleuven.be/mecenaat/leerstoelen/overzicht.htm).

None of the authors have a conflict of interest with regard to the data presented in this paper.

\section{References}

1 O'Brien E, Asmar R, Beilin L, Imai Y, Mallion JM, Mancia G, et al. European Society of Hypertension recommendations for conventional, ambulatory and home blood pressure measurement. J Hypertens 2003; 21:821848.

2 Hansen TW, Jeppesen J, Rasmussen S, Ibsen H, Torp-Pedersen C. Ambulatory blood pressure and mortality: a population based study. Hypertension 2005; 45:499-504.

3 Sega R, Faccheti R, Bombelli M, Cesana G, Corrao G, Grassi G, et al. Prognostic value of ambulatory and home blood pressures compared with office blood pressure in the general population. Follow-up results from the Pressioni Arteriose Monitorate e Loro Associazione (PAMELA) Study. Circulation 2005; 111:1777-1783.

4 Dolan E, Stanton A, Thijs L, Hinedi K, Atkins N, McClory S, et al. Superiority of ambulatory over clinic blood pressure measurement in predicting mortality. The Dublin Outcome Study. Hypertension 2005; 46:156161.

5 Clement DL, De Buyzere ML, De Bacquer DA, de Leeuw PW, Duprez DA, Fagard $\mathrm{RH}$, et al. Prognostic value of ambulatory blood-pressure recordings in patients with treated hypertension. N Engl J Med 2003; 348:2407-2415.

6 Mancia G, Facchetti R, Bombelli M, Grassi G, Sega R. Long-term risk of mortality associated with selective and combined elevation in office, home and ambulatory blood pressure. Hypertension 2006; 47:846-853.

7 Ohkubo T, Kikuya K, Metoki H, Asayama K, Obara T, Hashimoto J, et al. Prognosis of 'masked' hypertension and 'white-coat' hypertension detected by 24-h ambulatory blood pressure monitoring. 10-year follow-up from the Ohasama study. J Am Coll Cardiol 2005; 46:508-515.

8 Staessen JA, O'Brien ET, Amery AK, Atkins N, Baumgart P, De Cort P, et al. Ambulatory blood pressure in normotensive and hypertensive subjects: results from an international database. J Hypertens 1994; 12 (Suppl 7): $\mathrm{S} 1-\mathrm{S} 12$.

9 Li Y, Wang JG, Guo HF, Nawrot T, Wang GL, Qian YS, et al. Are published characteristics of the ambulatory blood pressure generalizable to rural Chinese? The JingNing population study. Blood Press Monit 2005; 10:125-134.

10 Chen CH, Ting CT, Lin SJ, Hsu TL, Chou P, Kuo HS, et al. Relation between diurnal variation of blood pressure and left ventricular mass in a Chinese population. Am J Cardiol 1995; 75:1239-1243.

11 Li Y, Staessen JA, Li LH, Gao PJ, Thijs L, Brand E, et al. Blood pressure and urinary sodium excretion in relation to the $A-1984 \mathrm{G}$ adrenomedullin polymorphism in a Chinese population. Kidney Int 2006; 69:1153-1158.

12 Kuznetsova T, Malyutina S, Pello E, Thijs L, Nikitin Y, Staessen JA. Ambulatory blood pressure of adults in Novosibirsk, Russia: interim report on a population study. Blood Press Monit 2000; 5:291-296.

13 O'Brien E, Mee F, Atkins N, O'Malley K. Evaluation of the SpaceLabs 90202 noninvasive ambulatory recorder according to the AAMI Standard and BHS criteria. J Hum Hypertens 1991; 5:223-226.

14 Fagard R, Brguljan J, Thijs L, Staessen J. Prediction of the actual awake and asleep blood pressures by various methods of $24 \mathrm{~h}$ pressure analysis. J Hypertens 1996; 14:557-563.

15 Thijs L, Staessen J, Fagard R. Analysis of the diurnal blood pressure curve. High Blood Press Cardiovasc Prev 1992; 1:17-28.
16 McArdle WD, Katch FI, Katch VL. Exercise physiology. Energy, nutrition, and human performance. Philadelphia, Pennsylvania, USA: Lea and Febiger; 1991.

17 Staessen J, O'Brien E, Atkins N, Bulpitt CJ, Cox J, Fagard R, et al. The increase in blood pressure with age and body mass index is overestimated by conventional sphygmomanometry. Am J Epidemiol 1992; 136:450459.

18 MacMahon S, Peto R, Cutler J, Collins R, Sorlie P, Neaton J, et al. Blood pressure, stroke, and coronary heart disease. Part 1, prolonged differences in blood pressure: prospective observational studies corrected for the regression dilution bias. Lancet 1990; 335:765-774.

19 Mancia G, Grassi G, Giannattasio C, Seravalle G. Sympathetic activation in the pathogenesis of hypertension and progression of organ damage. Hypertension 1999; 34:724-728.

20 Safar ME. Peripheral pulse pressure, large arteries, and microvessels. Hypertension 2004; 44:121-122.

21 Masuo K. Obesity-related hypertension: role of the sympathetic nervous system, insulin, and leptin. Curr Hypertens Rep 2002; 4:112-118.

22 Zhang H, Thijs L, Kuznetsova T, Fagard RH, Li X, Staessen JA. Progression of hypertension in the nonhypertensive participants in the Flemish Study on Environment, Genes and Health Outcomes. J Hypertens 2006; 24:17191727.

23 Vasan RS, Larson MG, Leip EP, Kannel WB, Levy D. Assessment of frequency to progression to hypertension in nonhypertensive participants in the Framingham Heart Study: a cohort study. Lancet 2001; 358:16821686.

24 Björklund K, Lind L, Zethelius B, Andrén B, Lithell H. Isolated ambulatory hypertension predicts cardiovascular morbidity in elderly men. Circulation 2003; 107:1297-1302.

25 Hansen TW, Jeppesen J, Rasmussen F, Ibsen H, Torp-Pedersen C. Ambulatory blood pressure monitoring and risk of cardiovascular disease: a population-based study. Am J Hypertens 2006; 19:243-250.

26 Lurbe E, Torro L, Alvarez V, Nawrot T, Paya R, Redón J, et al. Prevalence, persistence, and clinical significance of masked hypertension in youth. Hypertension 2005; 45:493-498.

27 Staessen JA, Lijnen P, Thijs L, Fagard R. Salt and blood pressure in community-based intervention trials. Am J Clin Nutr 1997; 65 (Suppl):661S-670S.

28 Staessen J, Bulpitt C, Fagard R, Joossens JV, Lijnen P, Amery A. Four urinary cations and blood pressure: a population study in two Belgian towns. Am J Epidemiol 1983; 117:676-687.

29 Dyer AR, Elliott P, Shipley M, for the INTERSALT Cooperative Research Group. Urinary electrolyte excretion in $24 \mathrm{~h}$ and blood pressure in the INTERSALT Study. II. Estimates of electrolyte-blood pressure associations corrected for regression dilution bias. Am J Epidemiol 1994; 139:940-951.

30 Staessen J, Bulpitt CJ, Fagard R, Joossens JV, Lijnen P, Amery A. Contraceptive pill use, urinary sodium and blood pressure: a population study in two Belgian towns. Acta Cardiol 1984; 39:55-64.

31 Luft FC, Fineberg NS, Sloan RS. Estimating dietary sodium intake in individuals receiving a randomly fluctuating intake. Hypertension 1982 4:805-808.

32 Mancia G, Bertinieri G, Grassi G, Parati G, Pomidossi G, Ferrari A, et al. Effects of blood pressure measurement by the doctor on patient's blood pressure and heart rate. Lancet 1983; ii:695-698.

33 Parati G, Ulian L, Santucciu C, Omboni S, Mancia G. Difference between clinic and daytime blood pressure is not a measure of the white coat effect. Hypertension 1998; 31:1185-1189. 